\title{
Instruments for measuring quality of life, in relation to masticatory performance, elderly patients with removable dentures
}

\author{
Ilnstrumente de măsurare a calităţii vieţii, în relaţie cu performanţele masticatorii, \\ la pacienţii în vârstă protezaţi mobil
}

\author{
Alexandra Melania Oncescu Moraru, Cristina Teodora Preoteasa, Andreea Wagner, \\ Cătălina Murariu-Măgureanu, Daniela Meghea, Elena Preoteasa \\ Facultatea de Medicină Dentară, Universitatea de Medicină şi Farmacie „Carol Davila“, \\ Bucureşti, România
}

\begin{abstract}
Introduction. Oral health is an important part of human health. Aspects such as oral functionality, psychological and social impact, and wellbeing are all taken into account when defining the quality of life. The purpose of this study was identifying and analyzing the most used index for oral health related quality of life, containing items that assessed the masticatory function.

Method. PUBMED, Web of Science Core Collection, Google Scholar were the scientific databases used to establish the usage frequency of the indices OHIP, GOHAI, OIDP, DIDL, OHQOL-UK in researches on elderlies. Results. The most frequently used index for evaluating oral health related quality of life for the elders was OHIP (results: 820 in PUBMED, 567 in Web of Science; 10300 in Google Scholar). Other frequently used indices for this purpose were OIDP and GOHAI.

Conclusions. The instruments designed for evaluating oral health related quality of life are largely used, and found in the medical literature to be applied to patients with different characteristics and oral health status. These are used for evaluating populations or individual cases, and the subjective information highlighted by them can be correlated with objective data in relation to the patient or prosthetic outcome, as mastication, as an oral functional aspect that influences quality of life and everyday performance.
\end{abstract}

Keywords: old man, edentulous, questionnaire, indices, oral health-related quality of life

\section{REZUMAT}

Introducere. Sănătatea orală este o parte importantă a sănătăţii generale. Aspecte ce ţin de funcţionalitatea orală, impactul psihologic, social şi starea de bine a persoanei, sunt avute în vedere în definirea stării de sănătate orală în relaţie cu calitatea vieţii. Scopul studiului a fost identificarea şi analiza celor mai folosiţi in-dici destinaţi evaluării calităţii vieţii în relaţie cu sănătatea orală, care conţineau întrebări ce vizau evaluarea desfăşurării funcţiei masticatorii.

Metodă. S-au realizat căutări în bazele de date ştiinţifice PUBMED, Web of Science Core Collection, Google Scholar, pentru a analiza frecvenţa utilizării indicilor OHIP, GOHAI, OIDP, DIDL, OHQoL-UK la persoanele în vârstă.

Rezultate. Cel mai utilizat instrument de evaluare a calităţii vieţii în relaţie cu sănătatea orală la pacienţii în vârstă, interesând şi funcţia masticatorie, este indicele OHIP (rezultate: 820 în PUBMED, 567 in Web of Science; 10300 in Google Scholar). Alţi indici utilizaţi frecvent în acest scop sunt OIDP si GOHAI.

Concluzii. Instrumentele de evaluare a calităţii vieţii în relaţie cu sănătatea orală sunt larg utilizate şi prezentate în literatura de specialitate pentru diferite categorii de pacienţi şi afecţiuni orale. Acestea sunt utilizate la nivel de grup sau individual şi pot pune în evidenţă aspecte subiective ce pot fi corelate cu aspecte obiective ce ţin de pacient şi protezare, cum ar fi masticaţia, ca aspect funcţional oral ce se reflectă asupra calităţii vieţii şi performanţelor zilnice.

Cuvinte cheie: vârstnic, edentat total, calitatea vieţii în relaţie cu sănătatea orală, chestionar, indici 


\section{INTRODUCERE}

Sănătatea orală este o parte importantă, o componentă a sănătăţii generale, cu impact asupra calităţii vieţii. Aspecte ce ţin de funcţionalitatea orală, impactul psihologic, social şi starea de bine a persoanei în relaţie cu statusul oral sunt avute în vedere în definirea stării de sănătate orală în relaţie cu calitatea vieţii (1). De altfel, starea de sănătate a fost definită de Organizaţia Mondială a Sănătăţii (World Health Organization) în Constituţia adoptată în anul 1946 şi intrată în vigoare în anul 1948 ca „o stare completă de bine din punct de vedere fizic, psihic şi social, şi nu neapărat absenţa bolii sau infirmităţii“"(2).

Afectarea stării de sănătate orală şi impactul ei asupra calităţii vieţii este un aspect important ce trebuie cunoscut, evaluat pentru adoptarea celor mai potrivite conduite de tratament. Afectarea orală şi impactul ei asupra calităţii vieţii sunt aspecte diferite în funcţie de afecţiune, gradul ei de afectare, particularităţile individuale.

Pierderea dinţilor cu instalarea edentaţiei totale conduce la afectarea profundă a statusului oral, a performanţelor funcţionale, în principal masticatorii, dar şi ca estetică facială, având un puternic impact negativ asupra stării generale, nutriţionale şi calităţii vieţii individului în cauză. Protezările mobile convenţionale, cu neajunsurile lor legate de echilibrul precar al protezelor, limitările funcţionale, prin dificultăţile în asigurarea echilibrului protezelor şi performanţele masticatorii reduse, durerea sub proteze pot afecta calitatea vieţii pacienţilor protezaţi. La aceste aspecte legate de edentaţia şi protezarea totală convenţională se adaugă particularităţile generale ale pacienţilor, de regulă persoane în vârstă cu modificări fiziologice evolutive şi cu o patologie generală bogată, ce pun probleme deosebite în reabilitarea orală prin protezare, cuantificarea şi cunoaşterea interrelaţiei statusului oral $\mathrm{cu}$,starea de bine“ a pacientului fiind un aspect important pentru o mai corectă abordare terapeutică. Restabilirea aspectelor funcţionale orale prin protezare mobilă, restabilirea eficienţei masticatorii, constituie aspecte cu un impact important asupra stării de bine $(3,4)$. Schimbările tehnologice, cu noi posibilităţi de protezare, pe implanturi, cu îmbunatatiri ale aspectelor functionale, au condus la modificări pozitive asupra performanţelor masticatorii după protezare, dar şi în percepţia şi satisfacţia pacienţilor.

Complexitatea situaţiilor clinice, schimbările în percepţia pacienţilor, dar şi noile posibilităţi terapeutice, cu reabilitări mai performante funcţional, care pot da mai multă satisfacţie pacienţilor, fac necesară cuantificarea mai bună a situaţiilor clinice sub aspect funcţional, estetic, psihologic şi social cu impact asupra calităţii vieţii lor (5).

În edentaţia totală un obiectiv important în protezare este reabilitarea funcţională orală, asigurând condiţiile proprii de masticaţie, dar şi de fonaţie, cu restabilirea unui aspect estetic caracteristic pentru păstrarea încrederii în sine şi a interacţiunilor sociale. Masticaţia este un parametru central în protezarea edentatului total, ca fiind cea mai importantă funcţie orală care asigură condiţiile pentru o bună sănătate generală, dar şi o bună calitate a vieţii (6).

Având în vedere afectarea profundă a statusului oral, a masticaţiei prin pierderea dinţilor şi neajunsurile unor protezări mobile, cu impact asupra stării generale şi a stării de bine, aspecte frecvent intâlnite la persoanele în vârstă, ne propunem prezentarea de date publicate în literatura de specialitate referitoare la principalele instrumente utilizate în cuantificarea parametrilor orali în relaţie cu calitatea vieţii şi impactul lor asupra performanţelor zilnice, la această categorie de pacienţi.

Scopul studiului a fost identificarea şi analiza celor mai folosiţi indici destinaţi evaluării calităţii vieţii în relaţie cu sănătatea orală, fiind vizată identificarea celor realizaţi în formatul unui chestionar şi care conţineau întrebări care vizau evaluarea desfăşurării funcţiei masticatorii.

\section{MATERIAL ŞI METODĂ}

Pe baza literaturii de specialitate s-au realizat căutări pornind de la termenii utilizaţi în relaţie cu scopul studiului. Astfel, în căutare, pentru persoane în vârstă s-au folosit cuvintele cheie ,elderly“, ,aged“, ,aging“, „old“, „geriatric“, folosite împreună cu utilizarea operatorului boolean OR. Acestea s-au introdus în căutare folosind operatorul boolean AND cu acronimul celor mai cunoscute instrumente de evaluare a calităţii vieţii în relaţie cu sănătatea orală, care includeau şi evaluarea funcţiei masticatorii. 
Aceste instrumente de evaluare a calităţii vieţii au fost:

- OHIP (Oral Health Impact Profile),

- GOHAI (Geriatric Oral Health Assessment Index)

- OIDP (Oral Impacts on Daily Performance)

- DIDL (Dental Impact on Daily Living)

- OHQoL-UK (United Kingdom Oral HealthRelated Quality of Life)

Formula folosită în căutare a fost: ((()(elderly) OR aged) OR aging) OR old) OR geriatric) AND ,acronimul indicelui ce evaluează calitatea vieţii în relaţie cu sănătatea orală“،.

Bazele de date ştiinţifice folosite pentru căutări au fost: PUBMED, Web of Science Core Collection, Google Scholar. Căutarea a fost realizată în februarie 2019.

În urma căutării s-a înregistrat numărul de articole ca rezultate găsite, considerându-se că un număr mai mare de rezultate se traduce ca o utilizare mai mare a indicelui respectiv.

Evaluarea satisfacţiei pacientului în tratamentele orale şi cu precădere prin protezare, impactul lor asupra stării de sănătate orală şi asupra calităţii vietii, constituie preocupări importante ale specialiştilor. Pentru cunoaşterea satisfacţiei pacientului, după tratament, a calităţii vieţii lor, pe lângă evaluarea obiectivă a rezultatului obţinut, se realizează evaluare subiectivă, pe baza unor instrumente de culegere a datelor de tip chestionar. Sunt utilizaţi în acest scop indici epidemiologici în formatul menţionat anterior, utilizaţi atât pentru cunoaşterea fenomenelor de masă, dar şi cu relevanţă clinică, pentru a observa starea sau evoluţia unor cazuri individuale.

\section{REZULTATE}

Cel mai utilizat chestionar în vederea cunoaşterii aspectelor menţionate a fost identificat ca fiind OHIP, indiferent de baza de date ştiinţifică folosită pentru analiză (Web of Science Core Collection, Google Scholar).

De asemenea, chestionarele OIDP şi GOHAI au înregistrat o utilizare mare în cercetările publicate în reviste indexate în PUBMED şi Web of Science Core Collection, dar sub valorile inregistrate de chestionarul OHIP, iar DIDL a înregistrat o utilizare mare în cercetările publicate în reviste indexate în Google Scholar (Tabelul 1).
TABELUL 1. Rezultatele căutării de articole care utilizează indicii folosiți în evaluarea calității vieții în bazele de date ştiințifice

\begin{tabular}{|l|c|c|c|}
\hline \multirow{2}{*}{$\begin{array}{l}\text { Indice pentru } \\
\text { evaluarea calității vieții }\end{array}$} & \multicolumn{3}{|c|}{ Număr de articole } \\
\cline { 2 - 4 } & PUBMED & $\begin{array}{l}\text { Web of Science } \\
\text { Core Collection }\end{array}$ & $\begin{array}{l}\text { Google } \\
\text { Scholar }\end{array}$ \\
\hline OHIP & 820 & 567 & 10300 \\
\hline OIDP & 186 & 188 & 2330 \\
\hline GOHAI & 185 & 159 & 2080 \\
\hline DIDL & 14 & 12 & 4590 \\
\hline OHQOL-UK & 23 & 11 & 385 \\
\hline
\end{tabular}

\section{DISCUȚII}

OHIP (Oral Health Impact Profile), cel mai utilizat instrument de evaluare a calităţii vieţii în relaţie cu sănătatea orală, conform rezultatelor anterioare, este un instrument dezvoltat în anul 1994 în Australia de către GD Slade si AJ Spencer, în limba engleză (7). Acesta, în varianta iniţială cuprindea 49 întrebări care acopereau o arie largă de autoevaluare, ca evaluare subiectivă, a nivelului de disfuncţie, disconfort şi dizabilitate atribuit stării de sănătate orală (8).

Variantele indicelui OHIP ca număr de întrebări sunt în forma iniţială OHIP-49 cu 49 de întrebări şi ulterior formele cu număr din ce în ce mai redus de întrebări, mai precis OHIP-20, OHIP-14 şi de dată mai recentă OHIP-5. Indicativul numeric este folosit pentru a preciza numărul de întrebări ale indicelui conţinut de varianta (9).

Variantele mai scurte cu 14 şi respectiv 20 întrebari (OHIP-14, OHIP-20) prin numărul mai redus de întrebări, faţă de varianta originală, permit colectarea de informaţii într-un timp mai scurt, fără a pierde din acurateţea evaluării pe baza variantei originale.

Conceperea instrumentului OHIP a pornit de la modelul teoretic al lui Locker privind sănătatea orală, care avea în vedere 7 dimensiuni/domenii ale impactului sănătăţii orale asupra calităţii vieţii, respectiv: 1. limitări funcţionale (ex.probleme în masticaţie), 2. durere fizică (ex. durere sub proteză), 3. disconfort psihologic (ex.senzaţie de tensiune, de teamă), 4. dizabilităţi fizice (ex. schimbări ale dietei), 5. dizabilităţi psihologice (ex.putere de concentrare redusă), 6. dizabilităţi sociale (evitarea interacţiunilor sociale), 7. handicap (imposibilitatea de a lucra productiv) (8). Chestionarul OHIP-49 include 7 domenii cu câte 7 întrebări pentru fiecare 
domeniu. În chestionarul OHIP-14 întrebările fiecărui domeniu sunt în număr de două. Modelele mai noi privind calitatea vieţii în relaţie cu sănătatea orală includ 4 dimensiuni ale sănătăţii orale cu impact asupra calităţii vieţii, mai precis funcţionalitatea orală, durerea oro-facială, aspectul estetic şi impactul psiho-social. Aceste 4 dimensiuni au fost avute în vedere în conturarea variantei cele mai recente OHIP-5, varianta în care se reduce numărul de întrebări la $10 \%$ din numărul iniţial, dar care doreşte să surprindă $90 \%$ din informaţia redată de primul indice OHIP (9).

$\mathrm{O}$ variantă specială a OHIP este cea propusă de Allen şi Locker în 2002, destinată evaluării aspectelor menţionate la pacienţii edentaţi purtători de proteze mobile, varianta cunoscută sub denumirea de OHIP-EDENT (10). Realizarea acestei variante a pornit de la modelul Locker privind sănătatea orală şi include 19 de întrebări (11). OHIP-EDENT are ca subscale limitarea funcţională, durerea fizică, disconfortul psihologic, disconfortul fizic, disconfortul psihic, social şi starea de handicap.

$\mathrm{Cu}$ ajutorul chestionarelor OHIP este evaluat impactul sănătăţii orale în general asupra satisfacţiei pacientului şi calităţii vieţii lor. Intrebările cuprinse în toate chestionarele OHIP sunt formulate astfel încât să măsoare efectele menţionate în dimensiunea lor negativă, nu pozitivă. Răspunsurile sunt înregistrate pe o scală Likert cu 5 nivele, autorii indicând o codificare a acestora de la 0 la 4 (4 foarte des, 3 - destul de des, 2 - ocazional, 1 aproape niciodată şi 0 - niciodată), existând şi varianta de răspuns ,nu ştiu“, codificată ca valoare lipsă şi căreia i se alocă ulterior o valoare corespunzătoare mediei tuturor valorilor înregistrate la respectiva întrebare (8). Scorul total variază în funcţie de numărul de întrebari din chestionar. $\mathrm{Cu}$ cât scorul este mai mare, cu atât impactul problemelor ce ţin de sănătatea orală asupra calităţii vieţii este mai mare. Instrumentele OHIP în diversele lor variante au fost traduse în numeroase limbi şi validate (franceză, germană, spaniolă, portugheză, japoneză, română etc). Chestionarul OHIP-14 a fost validat în limba română şi publicate rezultatele în anul 2013 (12). OHIP s-a dovedit a fi un instrument valid de lucru şi în formulele mai scurte (13), demonstrând un grad bun de validitate interculturală (14).

OIDP (Oral Impacts on Daily Performance inventory) este un indice realizat de Adulyanon si
Sheiham în anul 1997, cuprinde 9 întrebări cu răspunsuri înregistrate pe scara Likert cu 6 categorii, evaluând performanţa masticatorie, fonatorie, igiena orală, somnul şi aspectul estetic (7). OIDP a fost folosit pe eşantioane de persoane în vârstă în cadrul mai multor cercetări anterioare, fiind demonstrat ca are bune proprietăţi psihometrice (15). Este indicat mai ales pentru a evalua nevoia de tratament (16).

GOHAI (Geriatric oral health assessment index) este un indice dezvoltat de KA Atchison şi TA Dolan (17). Acest instrument este destinat evaluării calităţii vieţii în relaţie cu sănătatea orală la persoanele la vârste înaintate, numite şi geriatrice. Chestionarul cuprinde un număr de 12 întrebări.

Realizarea acestui indice a avut în vedere ca domenii de interes ale sănătaţii orale cu impact asupra calităţii vieţii pe trei direcţii, şi anume: funcţionalitatea din punct de vedere fizic, cu referire la masticaţtie, fonatie si deglutitie (3 întrebări); functionalitatea din punct de vedere psiho-social (5 întrebări) şi durerea/disconfortul, având în vedere şi folosirea unor medicamente pentru ameliorarea simptomelor (4 întrebări) $(18 ; 16)$.

Răspunsurile sunt înregistrate pe o scară Likert cu 6 nivele: niciodată, rar, uneori, des, foarte des, întotdeauna (18).

\section{Analiza comparativa a indicilor OHIP, OIDP} si GOHAI. Indicii menţionaţi sunt instrumente folosite pe scară largă pentru evaluarea calităţii vieţii în raport cu sănătatea orală. Deşi la modul general vizează evaluarea aceluiaşi aspect, preferinţa autorilor către unul sau altul este în relație cu diverşi factori, cum sunt specificitatea mai mare de conţinut în relaţie cu un anumit aspect, formatul instrumentului de tip chestionar, ca număr de întrebări şi variante de răspuns. Administrarea lor nu ridică probleme etice (19).

Cercetări anterioare sugerează superioritatea unor variante ale OHIP comparativ cu OIDP. Astfel, dupa Hongxing et al. (20), OHIP-14 este similar ca fidelitate şi validitate de construcţie cu OIDP, dar superior acestuia din punct de vedere al validităţii de conţinut. Alte cercetări au identificat rezultate discordante. Astfel, după Montero et al. (21), OIDP are o validitate de conţinut superioară lui OHIP-14, iar după Lawal et al. (22) cele două instrumente sunt similare din punct de vedere al validităţii de conţinut.

Similar evaluării anterioare, OHIP şi GOHAI înregistrează existenţa de aspecte similare, dar şi 
diferenţe. După Locker et al. (23), ambii indici înregistrează valori semnificativ asociate cu percepţia subiectivă şi satisfacţia privind sănătatea orală, dar GOHAI pare a fi superior din acest punct de vedere pentru utilizarea lui în grupa de persoane foarte în vârstă, cu vârste de peste 80 de ani. După Rodakowska et al. (24), ambii indici înregistrează o consistenţă internă foarte bună, şi au capacitate de discriminare bună care favorizează surprinderea unei imagini exacte a statusului oral al pacienţilor în vârstă.

\section{CONCLUZII}

Instrumentele de evaluare a calităţii vieţii în relaţie cu sănătatea orală sunt larg utilizate şi prezentate în literatura de specialitate, pentru diferite cate- gorii de pacienţi şi afecţiuni orale. Cel mai utilizat instrument de evaluare a calităţii vieţii în relaţie cu sănătatea orală la pacienţii în vârstă protezaţi mobil este indicele OHIP. Alţi indici utilizaţi frecvent în acest scop sunt OIDP şi GOHAI.

Aceste instrumente sunt utile atât pentru a cunoaşte situaţia pacienţilor cu un anumit status oral la nivel de grup, dar pot fi folosite şi la nivel individual pentru a cunoaşte mai bine aspectele subiective ce pot fi corelate cu aspecte obiective ce ţin de pacient şi protezare, cum ar fi masticaţia, ca aspect funcţional oral ce se reflectă asupra calităţii vieţii şi performanţelor zilnice.

\section{Mențiune}

În realizarea articolului, toţi autorii au avut o contribuţie egală cu cea a primului autor.

\section{BIBLIOGRAFIE}

1. Sischo L, Broder HL. Oral health-related quality of life: what, why, how, and future implications. J Dent Res. 2011;90(11):1264-70.

2. World Health Organization. Constitution of the World Health Organization;1948. http://apps.who.int/gb/bd/PDF/bd47/EN/ constitution-en.pdf?ua=1.

3. Preoteasa CT, Preoteasa E, Meghea D, Marutescu L, Popa M, Pircalabioru G. Rom Biotech Lett. 2018;23(5):14067-71.

4. Preoteasa CT, Nabil Sultan A, Popa L, lonescu E, losif L, Ghica MV, Preoteasa E. Wettability of some dental materials. Optoelectron Adv Mat. 2011;5(8):874-8

5. Zani SR, Rivaldo EG, Frasca LC, Caye LF. Oral health impact profile and prosthetic condition in edentulous patients rehabilitated with implant-supported overdentures and fixed prostheses. J Oral Sci. 2009;51(4):535-43.

6. Preoteasa E, Magureanu Murariu C, Preoteasa CT, Moraru Oncescu $A$, losif $\mathrm{L}$. The importance of oral functional characteristics in treatment of completely edentulous patient. Romanian Journal of Stomatology. 2015;61(1):55-8

7. Bennadi D, Reddy CV. Oral health related quality of life. J Int Soc Prev Community Dent. 2013;3(1):1-6.

8. Slade GD. The oral health impact profile. In: Slade GD, ed. Measuring oral health and the quality of life. Chapel Hill: University of North Carolina, Dental Ecology, 1997.

9. Naik A, John MT, Kohli N, Self K, Flynn P. Validation of the Englishlanguage version of 5-item Oral Health Impact Profile. J Prosthodont Res. 2016;60(2):85-91.

10. Allen F, Locker D. A modified short version of the oral health impact profile for assessing health-related quality of life in edentulous adults. Int J Prosthodont. 2002;15(5):446-50.

11. Mesko ME, Patias R, Pereira-Cenci T. Is OHIP-EDENT similar to GOHAl when Measuring Ohrqol in Partial and Complete Denture Wearers? Dentistry. 2013;3:160. doi:10.4172/2161-1122.1000160

12. Slusanschi O, Moraru R, Garneata L, Mircescu G, Cuculescu M, Preoteasa $E$. Validation of a Romanian version of the short form of the oral health impact profile (OHIP-14) for use in an urban adult population. Oral Health Prev Dent. 2013;11(3):235-42.

13. Slade GD. Derivation and validation of a short-form oral health impact profile. Community Dent Oral Epidemiol. 1997;25(4):284-90.

14. Allison PJ, Locker D, Feine JS. Quality of life: a dynamic construct. Soc Sci Med. 1997;45(2):221-30.

15. Gülcan F, Nasir E, Ekbäck G, Ordell S, Asstrøm AN. Change in Oral Impacts on Daily Performances (OIDP) with increasing age: testing the evaluative properties of the OIDP frequency inventory using prospective data from Norway and Sweden. BMC Oral Health. 2014;14:59.

16. Palma PV, Caetano PL, Leite ICG. The Impact of Oral Health on Quality of Life: Questionnaires Most Commonly Used in the Literature. J Dent Health Oral Disord Ther. 2017;8(5):00298. DOI: 10.15406/jdhodt.2017.08.00298.

17. Atchison KA, Dolan TA. Development of the Geriatric Oral Health Assessment Index. J Dent Educ. 1990;54(11):680-7.

18. Niesten D, Witter D, Bronkhorst E, Creugers N. Validation of a Dutch version of the Geriatric Oral Health Assessment Index (GOHAI-NL) in care-dependent and care-independent older people. BMC Geriatr. 2016;16:53

19. Preoteasa CT, Buzea MC, Imre M, Ranga CR, Preoteasa E. Reporting ethics approval and informed consent of in vivo researches in dental journals. Rom J Leg Med. 2018; 26(3):323-328.

20. Hongxing L, List T, Nilsson IM, Johansson A, Astrøm AN. Validity and reliability of OIDP and OHIP-14: a survey of Chinese high school students. BMC Oral Health. 2014;14:158. doi: 10.1186/1472-683114-158.

21. Montero J, López JF, Vicente MP, Galindo MP, Albaladejo A, Bravo M. Comparative validity of the OIDP and OHIP-14 in describing the impact of oral health on quality of life in a cross-sectional study performed in Spanish adults. Med Oral Patol Oral Cir Bucal. 2011;16(6):e816-21.

22. Lawal FB, Taiwo JO, Arowojolu MO. Comparison of two oral health-related quality of life measures among adult dental patients. Oral Health Prev Dent. 2015;13(1):65-74.

23. Locker D, Matear D, Stephens M, Lawrence H, Payne B. Comparison of the GOHAI and OHIP-14 as measures of the oral health-related quality of life of the elderly. Community Dent Oral Epidemiol. 2001;29(5):373-81.

24. Rodakowska E, Mierzyńska K, Bagińska J, Jamiołkowski J. Quality of life measured by OHIP-14 and GOHAl in elderly people from Bialystok, north-east Poland. BMC Oral Health. 2014;14:106. doi: 10.1186/1472-6831-14-106. 